\title{
História clínica centrada no sujeito: estratégia para um melhor cuidado em saúde
}

\author{
Subject focused clinical history: strategy for a better health care
}

Bernardino Geraldo Alves Souto', Sissi Marília dos Santos Forghieri Pereira'

\begin{abstract}
Resumo
0 privilégio do mercado e da tecnologia para consumo que caracterizou o modelo de desenvolvimento social e econômico do século XX desumanizou uma série de práticas. Entre elas, a do cuidado à saúde. A ideia, agora, é redirecionar o progresso tecnológico e científico à pessoa como forma de garantir que tal desenvolvimento gere bem-estar e sirva à vida. Nessa direção, têm surgido propostas alternativas às vigentes para a abordagem de necessidades individuais de saúde. Uma delas sugere que as histórias clínicas destinadas à identificação dessas necessidades tenham como foco 0 sujeito em sua existência, de modo a compreender e abordar o adoecimento como um fenômeno existencial; uma visão muito além da doença como um evento. Objetivando contribuir para a humanização do cuidado à saúde das pessoas, este texto reflete sobre a questão posta acima e sugere uma sistemática para a construção de histórias clínicas centradas no sujeito, como alternativa à anamnese tradicional, em contribuição ao método clínico centrado na pessoa.
\end{abstract}

Palavras-chave: registros médicos; humanização da assistência; assistência centrada no paciente.

\section{Abstract}

The market privilege and consumption technology that characterized the social and economic development model of the twentieth century resulted in various inhuman practices. Among them, the health care. The idea now is to redirect the technological and scientific progress to the person as a way of ensuring that such development generates well-being and serve for life. In this direction, alternatives have emerged to the current approach of individual health needs. One suggests that the clinical histories for the identification of these needs should focus on the subject in his existence, in order to understand and address the illness as an existential phenomenon, a vision far beyond the illness as an event. Aiming to contribute to the humanization of health care, this text reflects on the question posed above and suggests a systematic approach to the construction of clinical histories focused on the subject, as an alternative to traditional history, in contribution to people-centered clinical method.

Keywords: medical records; humanization of assistance; patient-centered care.

Recebido em: 20/06/2011

Aprovado em: 01/11/2011

\footnotetext{
Trabalho realizado na Universidade Federal de São Carlos (UFSCar) - São Carlos (SP), Brasil.

1 Departamento de Medicina da Universidade Federal de São Carlos (UFSCar) - São Carlos (SP), Brasil.

Endereço para correspondência: Bernardino Geraldo Alves Souto - Rodovia Washington Luís, km 235 - Caixa Postal 676 - CEP: $13565-905$ -

São Carlos (SP),Brasil-E-mail: bernardino@ufscar.br; sissi@ufscar.br

Fonte de financiamento: nenhuma.

Conflito de interesse: nada a declarar.
} 


\section{Introdução e contexto}

É mencionada na literatura a observação de que a clínica no século XX foi influenciada a incorporar uma prática de certo modo objetivomaterialista, desenvolvida a partir da racionalidade biomédica centrada no orgânico, por meio da qual a doença é reconhecida, principalmente, a partir da afetação anatômica, bioquímica ou fisiológica de uma célula ou conjunto de células em seu ambiente histológico ${ }^{1-5}$.

Em certa medida, esse fenômeno estimulou o uso de tecnologias que valorizaram o consumo, às vezes abusivo, de equipamentos e insumos destinados à abordagem biomédica das doenças, frequentemente subtraindo o aproveitamento das possibilidades de cuidado relacionadas à promoção e à produção de qualidade de vida, saúde e equidade ${ }^{4}$.

Em muitos casos, esse caminho levou a uma cisão entre o sujeito e a vida, dicotomizando um em relação ao outro ao longo do processo de cuidado à saúde, permitindo, em várias oportunidades, reduzir a abordagem das necessidades clínicas de muitas pessoas aos limites do próprio corpo ${ }^{6}$. Nesse sentido, tornou-se comum a ocorrência de dificuldades na hora de lidar com fenômenos subjetivos no indivíduo que demanda por cuidado $o^{5,6}$.

Esse fato suscitou um movimento de retorno da clínica ao sujeito, no sentido de devolver a vida ao vivo e o ser à pessoa, por meio de uma prática que propõe o estabelecimento de um diagnóstico que vá além do âmbito biomédico e da prescrição de um tratamento objetivo; de uma prática capaz de alcançar o espaço da existência, além da vida e da morte como objetos, a partir de uma estratégia que busca identificar necessidades de saúde e propor um plano de cuidados ampliado e integral ${ }^{6}$.

Essa cristalização de um modelo de clínica adaptado ao modelo social hegemônico, conferiu às práticas médicas sob essa influência uma medida de reconhecimento, valorização e ajuste à sociedade suficiente para garantir a elas certa segurança e um poder típicos de quem reproduz o padrão estético objetivo. Neutralizou, desse modo, seu potencial transformador da existência por evitar a ampliação dos sentidos ${ }^{3,6}$.

Não obstante, o adoecimento não se resume, enquanto fenômeno existencial, a uma lesão ou disfunção celular objetivamente detectável por tecnologias materiais, não é função de consumo, não se adapta a regras de mercado e é intensamente impregnado de subjetividades. Sua compreensão e abordagem demandam, cada vez mais, recursos que vão além do biomédico e de suas respectivas tecnologias. Requer, por exemplo, grande participação das ciências humanas e sociais, ainda proporcionalmente pouco valorizadas na formação médica tradicional ${ }^{2,5}$.

Entre os instrumentos disponíveis à prática médica, capazes de ajudála a se refazer no âmbito da abordagem ampliada da pessoa em seu adoecimento, focalizou-se um que é bem simples e operacional: a técnica de obtenção de histórias clínicas. Ainda é frequente o encontro de histórias médicas que reduzem o sujeito a paciente e estreitam o campo visual da clínica à doença. Dessa forma, podem contribuir para afirmar o papel de consumidor de quem procura por cuidado, ainda que não explicitamente, e não atender às reais necessidades de saúde do indivíduo ou da coletividade ${ }^{1-3,6}$.
Ou seja, a entrevista médica precisa ultrapassar o perímetro de uma anamnese; um instrumento sistemático que não alcança o fenômeno do adoecimento por se limitar à descrição de fatos pouco contextualizados, e que, ainda, pode verticalizar o médico sobre o paciente ${ }^{7-8}$. Seu objetivo é a queixa principal. Seleciona, assim, o problema que pretende abordar a partir de uma visão organicista que prioriza o lado corporal da pessoa, muitas vezes desconectando-a do seu lado existencial, dando margem a uma relação assimétrica entre o médico e o paciente favorável ao primeiro. Desse modo, perde a oportunidade de considerar que os sintomas relatados por uma pessoa se apresentam impregnados por subjetividades relacionadas à experiência com a doença e com a própria comunicação com o médico. Isto é, as queixas do sujeito não traduzem somente sua sintomatologia física, mas, também, sentimentos e percepções que não encontram espaço adequado ou específico na estrutura formal da anamnese que se aprende nos currículos de graduação médica $^{3,6}$.

A queixa ou o problema escolhido pela anamnese é somente o principal. Ainda assim, em até $50 \%$ das vezes, médicos e pacientes chegam a discordar sobre esse problema principal por desconexão entre suas percepções de prioridade sobre o agravo de saúde em apelo, como óbvia consequência da assimetria da relação entre ambos ${ }^{7}$.

Por outro lado, se houver mais de uma queixa, talvez tenha de se fazer outra anamnese especificamente para esta, se considerarmos com rigidez a forma estruturada como esse instrumento é proposto. É difícil fazer uma anamnese partindo de mais de um problema. É fácil relatar a história da moléstia atual, mas é complicado relatar de maneira correlacionada, as histórias dos adoecimentos de modo a contextualizar tudo no sujeito em sua existência. Afinal, na anamnese comenta-se muito sobre a doença, mas, falta foco na existencialidade para dar sustentação ao conjunto que o sujeito representa e traz consigo enquanto ser existente que, por assim ser, enfrenta o fenômeno do adoecimento segundo sua cultura e personalidade ${ }^{1}$.

Considerando, pois, que o corpo é o equipamento por meio do qual produzimos e consumimos bens e serviços, e que a alma não serve tanto quanto a esse objetivo, as questões extracorporais que envolvem o processo de saúde e adoecimento encontram pouca oportunidade de abordagem em uma anamnese convencional; aquém, portanto, da real necessidade do cuidado. Apoiada por um exame físico voltado exclusivamente à lesão, funcionamento e estética do corpo, que não reconhece significados e representações corporais e tem dificuldade em relacionar determinados sinais com os sentimentos do sujeito ${ }^{2}$, a consulta médica deságua no diagnóstico de uma doença e na prescrição de um bem de consumo: um exame complementar ou um medicamento. Contudo, isso é só um subconjunto mínimo do cuidado, que nem sempre é o mais importante.

Se pensarmos que no tempo em que a vida era muito curta bastava cuidar da sobrevivência física imediata das pessoas, pode ser que essa abordagem tenha algum sentido histórico. O objetivo do cuidado em saúde restringia-se a socorrer a vida para que não encurtasse mais 
ainda. Contudo, com o aumento da sua duração, surgiu a demanda por sua qualidade, o que nem sempre está ao alcance da abordagem exclusivamente biomédica. Ou seja, antes cuidávamos da vida, mas, hoje cuidamos da existência; algo, portanto, muito maior. Precisamos, pois, atualizar nossos equipamentos e ampliar a compreensão sobre nosso objeto de trabalho, que já não é mais o mesmo3.

Não negamos a importância nem a utilidade da anamnese convencional, tampouco achamos que deva ser desprezada, mas, defendemos que se trata de uma ferramenta que precisa ser qualificada e atualizada às necessidades existenciais do nosso tempo que implicam no cuidado em saúde ${ }^{3}$.

A repressão dessa demanda, entre outros fatores, compromete a eficiência da prática médica, transformando-a em algo economicamente dispendioso e de questionável resolubilidade em termos de atendimento às expectativas e às necessidades de quem dela precisa ${ }^{3}$.

Para resgatar a clínica sequestrada pela política de consumo e trazê-la de volta ao cuidado, precisamos ampliá-la no âmbito do sujeito, conduzindo-a para além da doença ${ }^{2-4}$. O paciente é, apenas, uma parte do sujeito assim como a vida é somente uma parte da existência e a anamnese uma parte da história da pessoa ${ }^{3,4}$. A clínica precisa ser ampliada para cuidar da pessoa como um ser integral e assumir como objetivo a qualidade de vida do indivíduo, na compreensão existencial do próprio sujeito. Ou seja, precisa penetrar na subjetividade das pessoas onde se localizam os desejos e o projeto existencial de cada uma delas, cuja repressão sustentada pela estética social frequentemente induz a escapes psicossomáticos, o que, aliás, tem sido muito comum atualmente ${ }^{1-3,6}$. A anamnese tradicional não tem alcance para uma penetração dessa profundidade. De acordo com as ideias de Sanders, isso se dá porque a anamnese estruturada e o exame físico sistemático como se tem aprendido nos cursos de medicina concentram-se respectivamente numa narrativa e numa citação de fatos relacionados a sintomas e a sinais físicos. Subvalorizando, assim, a contextualização do adoecimento na história existencial do sujeito por meio da qual torna-se possível compreender não só a doença em sua fisiopatologia orgânica, mas, também, o porquê e como a doença entrou na vida da pessoa ${ }^{8}$. Ou seja, os sintomas e os sinais precisam ser comunicados, entendidos, interpretados e compartilhados; e não apenas decodificados à luz de um raciocínio fluxográfico ${ }^{2}$.

Precisamos, pois, transformar a consulta médica num encontro (forma horizontal de reconhecimento mútuo destinado a uma troca interpessoal) por meio do qual é possível corporificar uma história clínica capaz de decifrar o sujeito e, dentro dele, em sua existência, identificar suas necessidades de saúde ${ }^{6}$. Apoiada por um exame físico que, além da visão biológica do corpo, compreenda também seus significados e representações na percepção da pessoa examinada, essa entrevista permitirá a providência de um cuidado que servirá prioritariamente ao bem-estar existencial do sujeito.

Há que se entender, pois, bem-estar existencial como sendo uma qualidade de vida biológica, psicológica e social suficiente para que a pessoa possa, em sua plenitude, bem interagir consigo mesma, com os outros e com o ambiente.

$\mathrm{Na}$ assistência a uma pessoa, tendo como objetivo esse bem-estar, precisamos fazer mais do que um diagnóstico e uma prescrição. É necessário identificar necessidades de saúde e construir um plano de cuidados. Para isso, há que se entender, também, necessidades de saúde como um conjunto formado por elementos que demandam aplicação para que a pessoa ganhe qualidade de vida (necessidade de tratamento e reabilitação) tanto na esfera biológica quanto psicológica e social, e por elementos que demandam aplicação para que a pessoa não perca qualidade de vida (necessidade de promoção e prevenção) nas mesmas esferas; e plano de cuidados como um projeto negociado com o sujeito para encaminhamento dessas demandas que contemple ações de cuidado individual, cuidado coletivo, gestão da assistência e educação permanente do profissional e o do paciente. Essa negociação, por seu turno, deverá articular os desejos, as possibilidades e as necessidades que envolvem cada uma das necessidades de saúde identificadas.

Nessa trajetória, o médico constrói uma percepção ampliada da doença, de modo que esta deixa de ser um fato para se tornar um fenômeno no qual a disfunção não se restringe ao orgânico, mas, alcança também o ambiente psicológico, o cultural e o social da pessoa. Nesse sentido, é importante considerarmos que os sinais vistos no exame físico não complementam somente nossa compreensão sobre os sintomas relatados pela pessoa. Muitos desses sinais são produzidos pelos sentimentos do sujeito e mediados por sua cultura. Entretanto, não é comum que estejamos atentos aos sinais físicos da subjetividade, os quais traduzem as correspondentes abstrações presentes no relatório sintomatológico que, da mesma forma, escapam à nossa observação quando nos prendemos à estrutura formal de uma anamnese $\mathrm{e}^{2,3}$.

A esse respeito, McWhinney e Freeman, do Departamento de Medicina de Família da University of Western Ontário, consideram que a experiência com o cuidado é um fator importante para a habilidade do médico em desenvolver essa percepção ampliada e incorporá-la à história clínica ${ }^{2}$. Nesse sentido, e consoante às ideias de Sanders, Lopes reconhece que há médicos que adquirem essa desenvoltura, porém, muito mais por uma característica pessoal do que pela incorporação de uma tecnologia derivada de uma oportunidade formal de aprendizagem ${ }^{1,8}$.

No contexto dessa capacidade, nossa comunicação com aquele que cuidamos é estratégica ao entendimento do fenômeno que determina as necessidades de saúde deste, tanto quanto à eficácia e à eficiência do plano de cuidados, independentemente de qualquer precisão diagnóstica².

Ao mesmo tempo, a qualidade dessa comunicação é função do seu alcance. A comunicação precisa, pois, contemplar o espaço sociocultural daquele que cuidamos para que seja eficiente em identificar as necessidades de saúde desse sujeito e eficaz em colocar em prática um respectivo plano de cuidados ${ }^{2}$.

Sendo assim, para que a abordagem clínica seja capaz de servir ao bem-estar existencial, Perestrello propõe que, ao nos comunicarmos 
com as pessoas motivadas por um cuidado de saúde, transitemos entre as dimensões biológicas e psicológicas, além da psicossomática, incorporando, também, a dimensão antropológica, sem oposição ou negação do que se considerava anteriormente. Esse autor afirma que a medicina da pessoa vê o sujeito além do organismo; em vez de procurar causas, busca a totalidade; em vez de focalizar o estímulo-reação, a situaçãoexpressão. Enfim, advoga a favor de uma postura holística e uma atitude compreensiva?.

Nessa mesma direção, Campos traduz suas ideias da "Clínica do Sujeito", trabalhando com maior profundidade os conceitos filosóficos sobre a pessoa e com menor profundidade os aspectos psicológicos, em comparação com o que faz Perestrello. Entretanto, articula, da mesma forma, as dimensões biológicas, psíquicas e sociais. Para esse autor, a clínica do sujeito é ampliação e não troca - seu objeto de estudo é a síntese dialética entre o sujeito e sua doença. Faz, ainda, uma leitura da clínica, vista pelo olhar da saúde coletiva, em três dimensões: a oficial (ou hegemônica), preocupada com a doença; a degradada, que é a oficial degradada por interesses econômicos ou desequilíbrios de poder; e a clínica ampliada ou do sujeito. Defende que o desafio é passar do campo das certezas, de regularidades mais ou menos seguras (padrões) para o campo da imprevisibilidade da vida cotidiana, reconhecendo os limites de qualquer saber estruturado ${ }^{10}$. Fonseca e Kirst fazem essa mesma proposta quando o assunto é cuidado individual ${ }^{6}$.

Campos também coloca a clínica como arte e faz o contraponto de que se lidamos com vidas, devemos dar importância ao conhecimento disponível sobre os aspectos genéricos dos processos saúde-doençaatenção. Valoriza o saber das regularidades possíveis (conhecimento sistematizado disponível), mas relativiza a supremacia como tem sido colocado, inclusive na forma de protocolos. Amplia, assim, a perspectiva da saúde para a ação, além dos determinantes, e reforça a importância de aprender com a variação e com o singular, saber escutar e perscrutar o singular, decidir ponderando, ouvindo, expondo incertezas e compartilhando dúvidas. Ou seja, os saberes estabelecidos são bem-vindos desde que haja espaço para se duvidar deles. Desse modo, devemos agir apoiados nos protocolos, mas questionando-os ${ }^{10}$. Baseados nisso, reforçamos o argumento de que a anamnese tradicional, enquanto instrumento sistematizado padrão para levantamento de história clínica, precisa adequar sua forma de ser para que dê conta de abordar o sujeito contido no coletivo. Apesar dela captar razoavelmente a generalidade da média, é frágil em perceber aquilo que é único e individual ${ }^{8}$.

Essa adequação, consoante às ideias de José Mauro Cerati Lopes, especialista em Medicina de Família e Comunidade, contribui para um cuidado centrado na pessoa, o qual leva em consideração a personalidade do sujeito com necessidades de saúde e o efetiva como parceiro no contexto do projeto terapêutico sem desprezar o conhecimento sistematizado. Esse tipo de cuidado torna a clínica mais eficiente em alcançar seus objetivos no âmbito biológico, psicológico e da relação do médico com a pessoa que demanda por atenção, bem como em pôr em prática sua idoneidade social ${ }^{1}$.
Portanto, converter a anamnese tradicional em uma história clínica centrada no sujeito, além de qualificar a prática médica, caracteriza-se como uma postura de respeito à autonomia da pessoa e demais direitos humanos, assim como aos ideais democráticos de cidadania no ambiente existencial de quem precisa de cuidados de saúde; ou seja, de todos e de cada um de nós ${ }^{6}$.

Essas ideias são corroboradas pelo argumento da dra. Sanders, da Faculdade de Medicina de Yale, assim como as de McWhinney e Stewart, de que a abertura da ação médica ao sujeito que dela necessita dá oportunidade para que o plano de cuidados conte com a colaboração desse interessado, potencializando a resolubilidade da própria ação médica ${ }^{2,3,8}$.

Nesse sentido, a história clínica deve ser traduzida para a linguagem e para o contexto de vida da pessoa sob cuidado para que o médico consiga ajudá-la efetiva e eficientemente. Essa tradução garante que o autor da história clínica seja o próprio sujeito, o qual, ao retornar a esse autor no processo do cuidado, o permite tomar consciência, compreender e intervir sobre o fenômeno do adoecimento em torno de si ${ }^{8}$.

Esse movimento, que deve ser desencadeado pelo médico, tem início na entrevista clínica que, segundo McWhinney e Freeman, tem o papel inicial de descobrir a pessoa e não só identificá-la. Não obstante, essa descoberta não é possível se o foco limitar-se a um conjunto de sinais e sintomas ancorados prioritariamente numa queixa principal. É preciso compreender esse conjunto no contexto existencial de quem os apresenta. Portanto, a entrevista médica não pode ser transversal como a anamnese que conhecemos, mas precisa ampliar-se a cada encontro ao longo do processo de cuidado 2 .

\section{0 foco da abordagem em uma história clínica centrada no sujeito}

O encontro pressupõe um vínculo. Portanto, para se realizar uma entrevista clínica é necessário que, antes, estabeleça-se um vínculo entre o profissional de saúde e a outra pessoa. Esse vínculo é para, no mínimo, horizontalizá-los e aculturá-los como sujeitos relacionantes interessados no cuidado que se pretende propor a partir do encontro e compreender por meio da história clínica.

Esse processo precisa, pois, explorar a enfermidade em seu ambiente histórico, social e cultural, compreendendo-a à luz da experiência e das percepções do próprio sujeito. Ao identificar necessidades de saúde, valorizar elementos relacionados ao sofrimento, ao risco e à vulnerabilidade, e ao propor um plano de cuidado, fazê-lo conjuntamente com o interessado, de maneira negociada, compreendendo este como um ser existente e autônomo. Ao mesmo tempo, sustentar esse plano no princípio bioético da não maleficência, fortalecido pelo princípio ideológico da humanização e do direito. Isso pode ser feito por meio de um ajuste equilibrado entre as necessidades, as possibilidades, os desejos e as responsabilidades do profissional de saúde, do serviço de saúde e do próprio sujeito ${ }^{11}$. Em síntese, o encontro proporcionado pelo vínculo permite que se faça uma história clínica reflexiva que, con- 
tida na história de vida da pessoa, amplia a compreensão médica para além da doença; ou seja, para o fenômeno existencial do adoecimento. Uma história assim construída valoriza significados e representações da enfermidade e do risco (compreendido como contingência) e incorpora o conceito de vulnerabilidade (autonomia do sujeito sobre o risco). Consegue compreender, pois, as percepções da pessoa a respeito da doença e trabalhar o adoecimento e a morte como processos existenciais; portanto, contextualizados ao ambiente e ao cotidiano da vida.

Para isso, é preciso conhecer a pessoa, os que estão à sua volta e o meio em que vive, compreender a interação do sujeito consigo mesmo, com quem está à sua volta e com o meio em que vive, assim como os fundamentos dessa interação. A partir daí, identificar o que pode ser feito para que essa pessoa tenha um melhor bem-estar existencial e, em cima disso, negociar um plano de cuidado integral.

\section{Questões práticas para a realização de uma história clínica centrada no sujeito}

Para começo de conversa, devemos evitar as seguintes perguntas, comuns em uma anamnese tradicional:

a) "Qual a sua queixa principal?"

b) "O que é que o senhor tem?"

c) "Qual o seu problema?"

d) "O que é que o trouxe aqui??"

e) "Por que veio me procurar?"

Sugerimos que uma boa pergunta seja:

"O que é que o senhor gostaria de me contar a seu respeito?". Em seguida, ficar calado, só ouvindo, detectando os sentidos e significados contidos nas palavras do entrevistado². Evitar, no início, perguntas dirigidas, também comuns na anamnese, como: "Quando começou?"; "Como começou?”; "O que é que o senhor faz para melhorar?” etc $^{1,2,11}$.

No próximo momento, demonstrar sensibilidade e apreço ao relato do sujeito e buscar um elo de identificação com a pessoa e sua história. A partir daí, dirigir perguntas aos sentidos e significados observados nos planos biológico, psicológico e sóciocultural, articulando esses planos entre si no contexto existencial da pessoa, à luz das percepções dela mesma ${ }^{2}$.

Numa anamnese tradicional, essa fase da construção da história médica limita-se, apenas, a uma checagem de dados em busca de uma fisiopatogenia orgânica que leve à hipótese diagnóstica de alguma doença.

Não obstante, ao ampliar o escopo da abordagem dos problemas de uma pessoa por meio de uma história clínica centrada no sujeito, não é necessário nem possível levantar e compreender tudo em curto prazo ou simultaneamente. Vínculo, encontro, necessidades de saúde e plano de cuidado, contextualizados à existência, necessariamente são projetos longitudinais que pressupõem continuidade e acumulação ao longo do tempo ${ }^{2}$. Portanto, há que se ter habilidade para hierarquizar os problemas que afetam a qualidade e a segurança da vida da pessoa, de modo a definir, junto com ela, as prioridades do cuidado.

Durante a entrevista e o exame físico, sistematizar os problemas encontrados de modo a organizá-los em: transversais ou longitudinais; significação para o médico e para o sujeito; inserção na história da pessoa; e abordabilidade ${ }^{1,2,11,12}$.

Entendendo-se como problemas aquelas questões cuja abordagem melhorará a qualidade de vida do sujeito, ou impedirá que este perca qualidade de vida, tal organização facilitará a identificação das necessidades de saúde e a gestão do plano de cuidado.

Em termos práticos, substituir o roteiro da anamnese tradicional (queixa principal, história da moléstia atual, história patológica pregressa etc.) e do exame físico tradicional (exame físico geral e específico por órgãos ou sistemas), por uma entrevista e um exame físico semiestruturados a partir dos seguintes elementos (adaptado de Lopes, 2007)':

\section{Levantamento subjetivo:}

- $\quad$ história de vida;

- história clínica, pregressa e atual, contextualizada à história de vida.

\section{Levantamento objetivo:}

- exame físico geral e conduzido por problemas, significados e percepções.

\section{Compreensão do fenômeno:}

- problemas biológicos, psicológicos e sociais;

- percepção do sujeito sobre sua situação e seus problemas;

- percepção do médico sobre o sujeito e seus problemas;

- possibilidades para a abordagem dos problemas.

\section{Plano de cuidado:}

- abordagem negociada e realista dos problemas identificados, considerando os contextos biológicos, psicológicos e socioculturais no ambiente articulado pelos desejos, necessidades e possibilidades, com o objetivo de reduzir sofrimento, risco e vulnerabilidade, garantir direitos humanos e melhorar a qualidade e a condição de vida.

\section{Repercussões de uma história clínica cen- trada no sujeito sobre o plano de cuidados}

A coleta de uma história clínica centrada no sujeito permite que flua, automaticamente, ao final dela, um rol de necessidades de saúde. Dessa forma, facilita o processo de identificação dessas necessidades, configuradas por um conjunto de problemas que demandam abordagem a interesse da qualidade e da condição de vida da pessoa. 
Essa facilitação potencializa o plano de cuidados no sentido de gerar demandas de mobilização de equipe multiprofissional, de identificação de redes de apoio e de qualificação do processo assistencial, de educação permanente para o profissional ou equipe que provê o cuidado e de ações coletivas de saúde, além do próprio cuidado do indivíduo.

Há que se compreender, entretanto, que tudo isso é tão dinâmico e ajustável quanto a própria existência, fato que torna o cuidado um processo (providência). Diferente, pois, do que estamos acostumados a chamar de atendimento (meio de consumo) e mais amplo do que uma consulta médica convencional (prestação de um serviço).

\section{Agradecimentos}

À professora Roseli Ferreira da Silva, do Departamento de Medicina da Universidade Federal de São Carlos (SP), Brasil.

\section{Referências}

1. Lopes JMC. A pessoa como centro do cuidado: a abordagem centrada na pessoa no processo de produção do cuidado médico em Serviço de Atenção Primária à Saúde. Porto Alegre: 2005. [Internet]. [cited 2011 Nov 08]. Available from: http://hdl.handle.net/10183/5873

2. McWhinney IR, Freeman T. Manual de Medicina de Família e Comunidade. 3a ed. Porto Alegre: Artmed; 2010. p. 471

3. Stewart M, Brown JB, Weston WW, McWhinney IR, McWhinney CL, Freeman TR. Medicina centrada na pessoa: transformando o método clínico. 2a ed. Porto Alegre: Artmed; 2010. p. 376.

4. Sanvito WL. Medicina contemporânea: uma abordagem crítica. Rev Bras Clin Med. 2009;7(2):71-3.

5. Nogueira Ml. As mudanças na educação médica brasileira em perspectiva: reflexões sobre a emergência de um novo estilo de pensamento. Rev Bras Educ Med. 2009;33(2):262-70.

6. Fonseca TMG, Kirst PG. 0 desejo de mundo: um olhar sobre a clínica. Psicol Soc. 2004;16(3):29-34.
7. Burack RC, Carpenter RR. The predictive value of the presenting complaint. J Fam Pract. 1983;16(4):749-54.

8. Sanders L. Todo paciente tem uma história para contar: mistérios médicos e a arte do diagnóstico. Rio de Janeiro: Jorge Zahar; 2010. p. 325.

9. Perestrello D. A medicina da pessoa. 5a ed. São Paulo: Editora Atheneu; 2006

10. Campos GWS. Saúde paidéia. São Paulo: Hucitec; 2003.

11. Grupo Hospitalar Conceição. Gerência de Ensino e Pesquisa. Proposta pedagógica de educação permanente da GEP/GHC. Porto Alegre; 2005.

12. García C. Medicina centrada en el paciente. Relación médico-paciente, atención médica basada em la diversidad cultural y analfabetismo. In: Rubinstein A, Terrasa S. Medicina familiar e práctica ambulatória. 2a ed. Buenos Aires: Médica Panamericana; 2006. p. 55-63. 